\title{
Research
}

\section{A Geographic Model to Assess and Limit Cumulative Ecological Degradation from Marcellus Shale Exploitation in New York, USA}

\author{
John B. Davis $^{1,2}$ and George R. Robinson ${ }^{1}$
}

\begin{abstract}
When natural resources are exploited, environmental costs and economic benefits are often asymmetric. An example is apparent in the environmental impacts from fossil fuel extraction by hydraulic fracturing. So far, most scrutiny has been focused on water quality in affected aquifers, with less attention paid to broader ecological impacts beyond individual drilling operations. Marcellus Shale methane exploitation in New York State, USA, has been delayed because of a regulatory moratorium, pending evaluation that has been directed primarily at localized impacts. We developed a GIS-based model, built on a hexagonal grid underlay nested within the U.S. Environmental Protection Agency's EMAP system, to examine potential cumulative ecological impacts. In a two-step process, we characterized $>19,000$ hexagons, each sized to approximate the footprint of one drilling site $\left(2.57 \mathrm{~km}^{2}\right)$, using ecological attributes; we then developed a method for apportioning resource access that includes assessments of cumulative ecological costs. Over one-quarter of the hexagons were excluded as off-limits on the basis of six criteria: slope suitability, regulated wetland cover, protected-land cover, length of high-quality streams, mapped road density, and open water cover. Three additional criteria were applied to assess the estimated conservation vulnerability of the remaining sites: density of grassland birds (North American Breeding Bird Survey), percent core forest (Coastal Change Analysis Program), and total density of all state-mapped streams; these were determined and used in combination to rank the 14,000 potentially accessible sites. In a second step, an iterative process was used to distribute potential site access among all towns (sub-county governments) within the Marcellus Shale Formation. At each iteration, one site was selected per town, either randomly or in rank order of increasing vulnerability. Results were computed as percent cumulative impact versus the number of sites committed and compared to a most-conservative selection process (ranked by statewide conservation vulnerability). Random selection with proportional distribution by town resulted in larger cumulative ecological impacts, but rank-ordered selection by town was in many ways comparable to selection by statewide conservation vulnerability ranking. These outcomes allow for a political solution for managing resource access fairly, based on a balanced geographic distribution of economic benefits, coupled with an underlying scientific basis for assessing the ecological costs that are publicly shared.
\end{abstract}

Key Words: Core forest, hexagon land-cover grid, hydraulic fracturing, Marcellus Shale formation, natural resource sharing, New York State, sensitive species and ecosystems

\section{INTRODUCTION}

Land-use change often outpaces the capacity to track effects on land cover and subsequent ecological impacts. Ecologists are then left with the task of damage assessment while making little or no contribution to land-use planning. As a result, opportunities to protect and preserve vital ecosystem services and biodiversity are missed (e.g., Miller et al. 2009, Nelson et al. 2009). In parallel, socio-political systems have their own inadequacies when addressing rapid land-use changes, as is evident in a common environmental dilemma: the lack of balance in regulatory costs and benefits (Kraft 2004). In the latter case, early entrants into an exploitation phase reap immediate benefits, whereas later entrants suffer the bulk of regulatory burdens. Politicians and policy makers are sensitive to this imbalance and are reluctant to limit opportunities for later entrants (Olson 1996), especially at local government levels, where many private land-use decisions are made (Briffault 1990). Ecosystem degradation accumulates in part because there are no pre-set limits, which would require ecologically based advanced planning in addition to policies that can be perceived as fair (Ludwig et al. 1993).
A new round of abrupt, widespread change in the North American landscape accompanies the proliferation of petroleum and gas wells that use hydraulic fracturing technologies, which allow the extraction of previously inaccessible fossil fuels. In the United States, many states are in various stages of exploitation, with their rural landscapes perforated by industrial activity, generally without comprehensive planning. Much of this activity has been exempted from federal oversight by targeted legislation (USEPA 2011); therefore, policies to plan and regulate the facilities are left to state and local governments. A gap is growing between the economic impetus to exploit these energy sources and the capacity to evaluate environmental impacts (Considine et al. 2009, Entrekin et al. 2011). Socio-cultural impacts, including legal disputes, will also require assessment (Jacquet and Stedman 2009); from press accounts, it appears that many local governments are unprepared and overwhelmed (e.g., Tavernise 2011, Urbina 2011a,b,c).

In Pennsylvania, the number of Marcellus Shale gas drilling permits nearly doubled from 768 in 2009 to 1366 in 2010, with 
2011 permits on pace for a further doubling (Pennsylvania Department of Environmental Protection, Marcellus Shale, http://www.portal.state.pa.us/portal/server.pt/community/ marcellus_shale/20296). It is estimated that a cumulative total of 60,000 new wells will be in place by 2030, and environmental scientists have been working to gain an overview and entry into statewide planning, with the goal of limiting future degradation to Pennsylvania's significant natural habitats (Johnson 2010). To its north, New York State contains a substantial area of largely unexploited gas reserves in its share of the Marcellus Shale formation, which spans over half its counties (Coleman 2011). A moratorium on new drilling has been in place for $2 \mathrm{yr}$, pending full review by the New York Department of Environmental Conservation (NYSDEC 2011).

So far, most political attention to environmental effects of shale exploitation has been directed at protecting aquifers, driven by the obvious need to regulate industries in the surface watersheds that supply New York City's drinking water (NYSDEC 2011) and by deep uncertainties over potential effects of hydraulic fracturing on groundwater supplies throughout the Marcellus formation (Soeder and Kappel 2009). New reports indicate direct contamination of groundwater aquifers via leakage from drilling operations in New York and Pennsylvania (Osborn et al. 2011), and drinking water quality seems likely to remain the focus of future research. However, broader environmental consequences may need to be addressed as well, such as other forms of pollution (e.g., Cole 2010, Entrekin et al. 2011) and geological instability (Fountain 2012).

Deep shale gas extraction operates at relatively local scales, somewhat comparable to the many small, low-production petroleum wells scattered across the continental United States. Drilling sites and their underground reaches occupy areas in the range of hectares and square-kilometers, respectively (USEPA 2011; Pennsylvania Department of Environmental Protection, Marcellus Shale, http://www.portal.state.pa.us/portal/ server.pt/community/marcellus shale/20296), and so generally fit into single rural properties with individual ownership. Exploitation access agreements are often made with single families, whereas the resource itself is broadly distributed. Borrowing from the natural resource sharing framework of Leach et al. (1999), a broadly distributed endowment (natural gas) becomes an entitlement for those with direct access, made possible by the capability introduced by capitalized contractors. In contrast, degradation of broadly distributed ecological resources, the endowments and entitlements of all citizens, is shared equally but with limited shared capability to prevent or repair degradation. Within local communities, some ecological impacts of gas exploitation may seem minor, but the cumulative burden needs to be assessed out of fairness to the full public.
Jurisdiction over individual well siting is a somewhat gray area. New York State Environmental Conservation Law Section 23-0303, Article 2, states that the Department of Environmental Conservation "shall supersede all local laws and ordinances relating to the regulation of the oil, gas and solution mining industries; but shall not supersede local government jurisdiction over local roads or the rights of local governments under the real property tax law." In its Declaration of Policy (23-2703), Article 23 Oil, Gas, and Solution Mining Law, Title 27, Section 1, states that local governments are entitled to enact and enforce pertinent zoning ordinances, but that state government is charged with "protection and enhancement of wildlife and aquatic resources." Uncertainty over the powers of local government and the rights of land owners has spurred the formation of land-owner coalitions (Jacquet and Stedman 2009). However, environmental impacts will be shared across the state, and a transparent and fair approach to Marcellus Shale access can help balance cumulative costs against individual benefits.

Our goal was to produce a statewide model to assess cumulative ecological impacts of Marcellus Shale exploitation across New York and to display the results as policy options within a framework of fairly shared costs and benefits. Here, we describe a method for assessing cumulative ecological degradation and test whether a rational, ordered site selection system can reduce ecological impacts within a framework of fair and balanced distribution of resources access. We relied on publicly available information, but our study may be unique in its proactive perspective and approach.

\section{METHODS}

\section{GIS model}

The core element of our approach is a geographic information system (GIS) model incorporating both ecological and political features. The study area is defined by the boundaries of the Marcellus Shale formation within New York State, obtained from the U.S. Geological Survey (Coleman 2011), which includes 33 of 62 New York counties and 478 of 932 towns (sub-county governments). Natural features and political boundaries are both distributed unevenly and are not closely correlated, so fitting a model to estimate respective gas well footprints requires a grid system that can accommodate both.

Spence and White (1992) produced a hexagonal tessellation of the landscape of the conterminous United States for the Environmental Protection Agency's Environmental Monitoring and Assessment Program (EPA-EMAP). An array of hexagons is isotropic, provides even spatial coverage, and is less likely to be coincident with anthropogenic features such as jurisdictional boundaries or roads. Nested hexagon grids of larger and smaller scales can be generated relatively easily. The size of each hexagon in the original base grid was 
approximately $635 \mathrm{~km}^{2}$. Other authors have subsequently used nested hexagons of varying sizes (e.g., Schindler et al. 2008, Gould and Solórzano 2009, Nelson et al. 2009). We began with an overlay grid of $2.57-\mathrm{km}^{2}$ hexagons, nested within the EMAP system, as the units of analysis, for reasons described next.

The statutory requirement for density of well sites and spacing of wells is set forth in New York State Environmental Conservation Law, Article 23, Title 5, as amended in 2008. The minimum allowed spacing for vertical wells is one per 40 acres (17 ha). However, spacing units for horizontal drilling, with multiple wells set on a common drilling pad, require up to 640 acres (259 ha) to avoid overlap with adjoining operations (New York State Department of Environmental Conservation downloadable well data, http://www.dec.ny.gov/ energy/1603.html). Additional infill wells may be drilled within the spacing unit, but it is anticipated that the well density will be less than 16 wells. This is consistent with findings in Pennsylvania (Pennsylvania Department of Environmental Protection, Marcellus Shale, http://www.portal.state.pa.us/portal/ server.pt/community/marcellus shale/20296), where spacing units range from 105-251 ha. We began with the largest estimated drilling area $\left(2.59 \mathrm{~km}^{2}\right)$ and used the EMAP algorithm to build a grid. To keep hexagons nested within the EMAP base grid, the closest feasible size was $2.57 \mathrm{~km}^{2}$.

A total of 19,318 hexagons covered the study area, which was evaluated in two stages. First, hexagons containing natural features judged to be particularly vulnerable to the effects of natural gas development, or those hexagons located in areas where drilling is unlikely for practical reasons, were excluded from further analysis. Second, the remaining hexagons were evaluated for shared attributes that indicate a potential for ecological degradation from gas resource development. Three suitable parameters were identified that are covered by comprehensive, publicly available, statewide data sets. Using these data sets, we modeled loss and fragmentation of forest cover, contamination of streams, and disturbance to wildlife of conservation significance.

\section{Exclusion procedure}

Hexagons with any one of the following characteristics were excluded from further analysis as being too sensitive for energy development: > 50\% cover of mapped freshwater wetlands, $>50 \%$ cover of lakes and major rivers, $>50 \%$ cover of protected lands, $>50 \%$ of topography in slopes $>15 \%, \geq 1$ $\mathrm{km}$ cover of high-quality stream, or $0 \%$ cover of mapped roads. We used open-access spatial data sets and included data from the Commonwealth of Pennsylvania to apply consistent evaluation of hexagons spanning the two-state border. Explanations for the six exclusion criteria follow.

Freshwater wetlands

Vector features were derived from the New York State Freshwater Wetlands Maps as described in Article 24-0301 of the Environmental Conservation Law (New York State Department of Environmental Conservation maps located in the Cornell University Geospatial Information Repository, http://cugir.mannlib.cornell.edu/datatheme.jsp?id=111) or from the National Wetlands Inventory (NWI) in Pennsylvania (USFWS 2009). NWI coverage is incomplete for the full Marcellus Shale area of New York, so could not be used for that state. In New York, wetlands $\geq 5$ ha are regulated, and we used this as a general inclusion rule for all wetland features, including those that overlap with Pennsylvania. Within the study area, there are approximately $1525 \mathrm{~km}^{2}$ of wetlands fitting these conditions. Natural wetlands are one of the most diminished land forms in the northeastern United States (Gibbs 2000 ) and are also potentially very sensitive to the physical disturbance and chemical contamination associated with gas extraction.

\section{Area hydrography}

A vector file was assembled for hydrographic features such as lakes, ponds, reservoirs, and major rivers (PSIE 2008, New York State GIS Clearinghouse inventory data sets, http://gis.n y.gov/gisdata/inventories/details.cfm?dsid=49\&nysgis=). A $50 \%$ cover threshold was set because at that level, most pixels are in or adjacent to surface water bodies.

\section{Protected areas}

The Protected Areas Database of the United States (USGS 2009) includes geographic boundaries of public land ownership and voluntarily provided boundaries of private conservation lands. We used this data set to identify areas where drilling for shale gas would present conflicts with typical resource management goals for protection of biological, geological, cultural, scenic, and recreational resources. We cannot rule out the possibility that some management entities, public or private, may choose to allow shale exploitation. However, our objective was to explore scenarios at the town government level, so we felt further justified in this exclusion rule in that oversight of protected areas is generally beyond the purview of towns. Furthermore, potential economic benefits to local governments from exploitation on unprotected lands (e.g., fees and royalties) would probably not accrue from exploitation in most protected areas.

\section{Slope angle}

We used a $10 \times 10 \mathrm{~m}$ composite digital elevation model (DEM) to identify areas of steep slopes where it would be impractical to site gas wells. Individual 7.5-minute DEM tiles (USGS 2000; New York State Department of Environmental Conservation digital elevation models, available from the Cornell University Geospatial Information Repository, http:// cugir.mannlib.cornell.edu/datatheme.jsp?id=23) were converted to raster format and merged. The resulting mosaic was processed using ArcGIS Spatial Analyst tools to calculate the percent slope. Slopes were classified by comparing the digital 
elevation model with existing gas wells drilled since 2000 (New York State Department of Environmental Conservation downloadable well data, http://www.dec.ny.gov/energy/1603. html). More than $95 \%$ of New York's existing gas wells are located on sites with slope $<15 \%$. We judged that hexagons with $>50 \%$ surface cover in slopes $\geq 15 \%$ would be generally unsuitable locations for drilling operations.

\section{Water quality classifications}

All surface waters in New York State are assigned a water quality classification that denotes their best uses. Classes A, AA, A-S, and AA-S are considered suitable sources for drinking water if properly treated and are the highest classification of surface freshwater (New York State GIS Clearinghouse inventory data sets, http://gis.ny.gov/gisdata/in ventories/details.cfm?dsid=49\&nysgis=). In Pennsylvania, the corresponding data set is referred to as Designated Uses (PSIE 2008); the highest quality streams are designated Exceptional Value (EV) or High Quality-Cold Water Fishes (HQ-CWF). The New York and Pennsylvania data sets within the study area were merged. The highest quality streams were selected and intersected with the hexagons, and their total length was tabulated within each hexagon. Hexagons with $\geq$ $1 \mathrm{~km}$ total length of high-quality streams were excluded. At this density, most paths into and through a hexagon would have a high probability of encountering a high-quality stream; thus, measurable degradation could occur regardless of well siting.

\section{Road density}

In both New York and Pennsylvania, a digital vector file of public and private roads and streets is maintained by the state Department of Transportation (York State Office of Cyber Security, NYS Streets, http://gis.ny.gov/gisdata/inventories/details. cfm?dsid=932\&nysgis $=$, PADOT 2011a,b). We selected all roads from these data sets within the study area, merged the features, and intersected them with the hexagons. The total length of all roads within each hexagon was tabulated. Hexagons containing no digitally mapped roads were considered roadless, our threshold for exclusion.

\section{Selection criteria for conservation vulnerability models}

The remaining hexagons were evaluated according to three ecological parameters directly or indirectly related to biological conservation: core forest area, stream density, and grassland bird abundance, calculated for all nonexcluded hexagons.

\section{Core forest cover}

Core forest was estimated by tallying the total number of pixels in each hexagon belonging to the core forest category in the forest fragmentation layer of the Coastal Change Analysis Program 2006-era land cover data set (available from http://w ww.csc.noaa.gov/digitalcoast/data/forestfrag/index.html). The forest fragmentation layer is a raster data set $(30 \times 30 \mathrm{~m}$ pixels), derived from a reclassification performed by the
Coastal Services Center on the land-cover data set. The deciduous forest, mixed forest, evergreen forest, and palustrine forest classes were recoded to forest, with all remaining classes recoded to nonforest. The reclassified data set was then processed using the Landscape Fragmentation Tool Version 2.0 from the University of Connecticut (available from http://clear.uconn.edu/tools/lft/lft2/index.htm ). The final result of the analysis is a five-class layer: background, patch forest, perforated forest, edge forest, and core forest. An edge width of $30 \mathrm{~m}$ was used in the fragmentation tool analysis. Hence, core forest includes forest pixels that are $>30 \mathrm{~m}$ from the nearest nonforest pixel.

\section{Stream density}

Stream density was calculated using the same merged stream data set analyzed above to determine the lengths of the highest quality streams, in this case, without restrictions on quality. The total length of streams of all classes was tallied for each hexagon and normalized to the area of the hexagon $\left(\mathrm{km} / \mathrm{km}^{2}\right)$. Stream order is not directly available in the data sets employed, so we made no distinctions on this basis.

\section{Grassland bird abundance}

To map grassland bird abundance, we used the North American Breeding Bird Survey (BBS), Route Level Data Summaries 1966-2003, version 2004.1 (Patuxent Wildlife Research Center 2004). The BBS is the only wildlife survey for New York that is consistently applied over its full geographic range. The surveys are conducted during the peak of the nesting season, primarily in June. Each route is $45 \mathrm{~km}$ long, with a total of 50 stops located at $0.9-\mathrm{km}$ intervals along the route. A 3-min point count is conducted at each stop, during which the observer records all birds heard or seen within 0.45 $\mathrm{km}$ of the stop. Data are recorded at each stop and then totaled over the entire 50-stop route. The survey produces an index of relative abundance of nesting pairs, rather than a full census. Mean abundance within each hexagon was calculated for grassland species of conservation concern in New York State (Table 1) for all species pooled. Abundance of each species was estimated as an inverse distance-weighted average of counts from nearby survey routes over a $100 \times 100 \mathrm{~m}$ grid of points within the study area. The abundance grids were summed, and a mean was calculated for each hexagon.

\section{Overall conservation vulnerability ranking}

We used distributions of tabulated values of core forest cover, stream density, and grassland bird abundance to rank nonexcluded hexagons in order of vulnerability. The three parameters use different metrics and follow different distribution patterns (Fig. 1) and so cannot be treated additively. Therefore, ranks were determined for each parameter independently using percentiles. The three separate ranks were then summed to determine a unique overall rank for each nonexcluded hexagon, which we treated as a potential well site in the selection methods described next. 
Table 1. List of New York State grassland birds (Morgan and Berger 2008) represented in our vulnerability ranking procedure. (See Methods: Selection criteria for ecological degradation models: Grassland bird abundance).

\begin{tabular}{ll}
\hline \hline Scientific name & Common name \\
\hline Asio flammeus & Short-eared Owl \\
Circus cyaneus & Northern Harrier \\
Bartramia longicauda & Upland Sandpiper \\
Cistothorus platensis & Sedge Wren \\
Dolichonyx oryzivorus & Bobolink \\
Lanius ludovicianus & Loggerhead Shrike \\
Eremophila alpestris & Horned Lark \\
Sturnella magna & Eastern Meadowlark \\
Ammodramus henslowii & Henslow's Sparrow \\
Ammodramus savannarum & Grasshopper Sparrow \\
Passerculus sandwichensis & Savannah Sparrow \\
Pooecetes gramineus & Vesper Sparrow \\
\hline
\end{tabular}

\section{Selection criteria for policy options}

In the politics of resource sharing, perceptions of fairness may be strengthened by using methods of distribution that are transparent, unbiased, and based on measurable criteria. Our vulnerability rankings address publicly shared resources, but permission to access targeted natural gas resources depends on political decisions. Using the vulnerability-ranked hexagons, we tested whether an organized, rule-based method would be an improvement over the relatively haphazard methods of granting access that are currently used in Marcellus Shale exploitation. Available sites were selected in a sequence that permits one selection per town at each iteration, with and without ranking the hexagons on their vulnerability to loss of core forest, stream length, and grassland bird breeding pairs. For this procedure, nonexcluded hexagons were ordered in two ways: ranked per town in order of vulnerability, and randomly ordered per town; the latter was meant to mimic the relatively haphazard siting decision process that seems to be the current norm. Results of these two selection methods were compared with sites drawn simply in order of statewide vulnerability, without regard to location, which served as the most conservative approach modeled.

\section{Town-level selections}

To the extent that economic benefits from shale gas extraction are publicly shared, the beneficiaries are likely to be at the town or equivalent government level in New York State. Under this assumption, our first distribution rule was that all towns within the Marcellus Shale zone should have equal probability of benefiting from gas extraction in proportion to their potential access, defined simply as the number of nonexcluded hexagons per town. Frequency distributions were somewhat skewed, with a few towns accounting for a
Fig. 1. Frequency distributions of nonexcluded sites evaluated for three attributes. (A) Percent of core forest cover, (B) total stream length, (C) abundance of grassland birds of conservation concern (see Methods: Selection criteria for ecological vulnerability models).
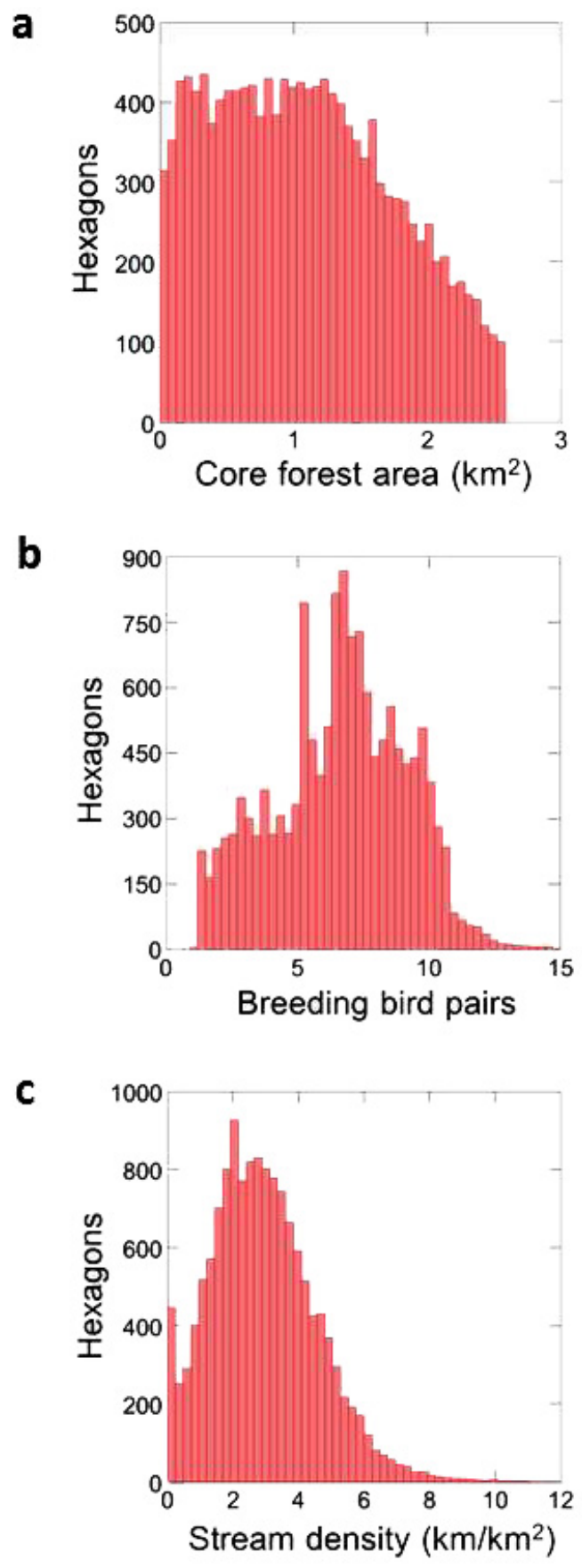
larger fraction of available hexagons (Fig. 2). Eleven of the 478 local government jurisdictions are classified as cities (New York State Office of Cyber Security, NYS Civil Boundaries, http://gis.ny.gov/gisdata/inventories/details.cfm? dsid=927\&nysgis=). These had the lowest counts and, in sum, contained a small fraction of available sites (Fig. 2). Therefore, we did not make further distinctions and instead grouped them with towns (hereafter, town refers to local government units smaller than the county level, including both cities and towns).

Fig. 2. Frequency distribution of nonexcluded hexagons per town in each of 478 New York towns (subunits of counties). Hexagons encompassing sites classified as urban (11 cases) are shaded in blue.

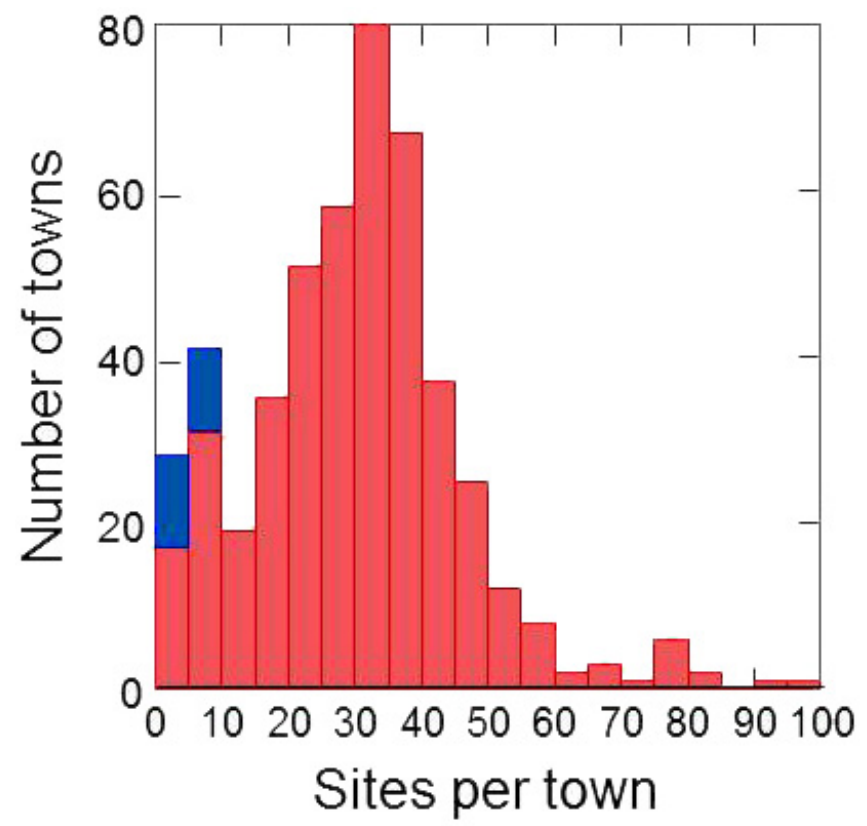

We designed a selection algorithm that chooses one site per town at each step in a cumulative process, calculating the estimated amount of lost core forest, degraded stream density, and grassland bird breeding pairs. At each iteration, one hexagon was added for each of the 478 towns, drawn from the remaining nonexcluded hexagons available per town. Under the random assignment method, we used the means of 10 different trials. Under the ordered assignment method, we began with the lowest impact site (hexagon with the lowest vulnerability rank) and ended with the highest impact site per town. For ease of display and interpretation, we graphed results in deciles of sites selected, assessing cumulative impacts with each addition of the next $10 \%$ of all potential well sites.

\section{Comparisons among selection methods}

The estimated outcomes at each of the 10 intervals were defined as (1) percent total statewide area of core forest disturbed, (2) percent of total statewide stream length disturbed, and (3) percent of grassland bird breeding pairs lost (interpreted as percent of total habitat disturbed, all species pooled). The outcome values were tabulated for comparison between the two town selection methods and the full statewide (most conservative) method. In this way, ecological cumulative costs were estimated under three resource distribution models. In addition, results of ordered selection at the town level were mapped at the 50\% threshold (protecting the most vulnerable half of nonexcluded hexagons) to view geographic patterns that resulted.

\section{Analytical tools}

All map development and output was prepared using ArcGIS v9.3.1 software (ESRI, Redlands, CA, USA). Vulnerability rankings and algorithms were prepared using MS Access Version 14 (Microsoft Corporation, Redmond, WA, USA). Statistical graphs prepared using SYSTAT 12 (Systat Software, Chicago, IL, USA).

\section{RESULTS}

\section{Exclusion procedure}

In all, 5268 hexagons were excluded from consideration, based on six attributes of sensitivity (Table 2), corresponding to approximately $27 \%$ of the total study area. This left 14,050 hexagons for further analysis. Excluded hexagons are distributed across the study area, but two large concentrations are located in the Catskill Mountains and surrounding Allegheny State Park in the southwest (Fig. 3). An additional set of 102 hexagons fell mostly in Pennsylvania, so were dropped from consideration, leaving 13,948 hexagons for our policy models.

\section{Selection procedure}

Using ordered selection by town, the mapped outcome at the upper 50\% conservation value $(\mathrm{CV})$ threshold (protecting the 6972 more vulnerable hexagons) results in two general geographic patterns (Fig. 3). First, the 6976 hexagons deemed less vulnerable (lower $50 \% \mathrm{CV}$ ) are well distributed across the study area such that all counties contain nonexcluded hexagons in the less vulnerable categories. Second, their relative distributions among counties are uneven, in part because some counties contain proportionally more excluded hexagons and in part because the more vulnerable $\mathrm{CV}$ hexagons are not evenly distributed.

For all three ecological criteria, selecting potential well sites purely on the basis of statewide vulnerability rank leads to lower levels of cumulative degradation compared to random selection at the town level. However, in each case, the relative differences vary. For example, if half of all potential well sites are exploited using random selection, the models estimate an extra $6 \%$ of core forest degradation, an extra $17 \%$ of stream degradation, and an extra $7.5 \%$ of grassland bird habitat degradation (Fig. 4). From a political perspective, it is more 
Fig. 3. Map of the study area, with underlying hexagonal grid, defined by the boundaries of the Marcellus Shale formation within New York State. $N=19,318$ hexagons. Excluded hexagons $(N=5286$, dark red) fall into one or more of six categories of high sensitivity to energy development (see Table 2). Green hexagons fall into the upper $50 \%$ of conservation value (higher vulnerability) rankings, ordered by town. Remaining hexagons (yellow) fall into the lower $50 \%$ of conservation value (lower vulnerability) rankings (see Methods: Selection criteria for conservation vulnerability models). Source: New York State Department of Environmental Conservation, Marcellus Shale formation 2009 production, http://www.dec.ny.gov/ energy/46381.html.

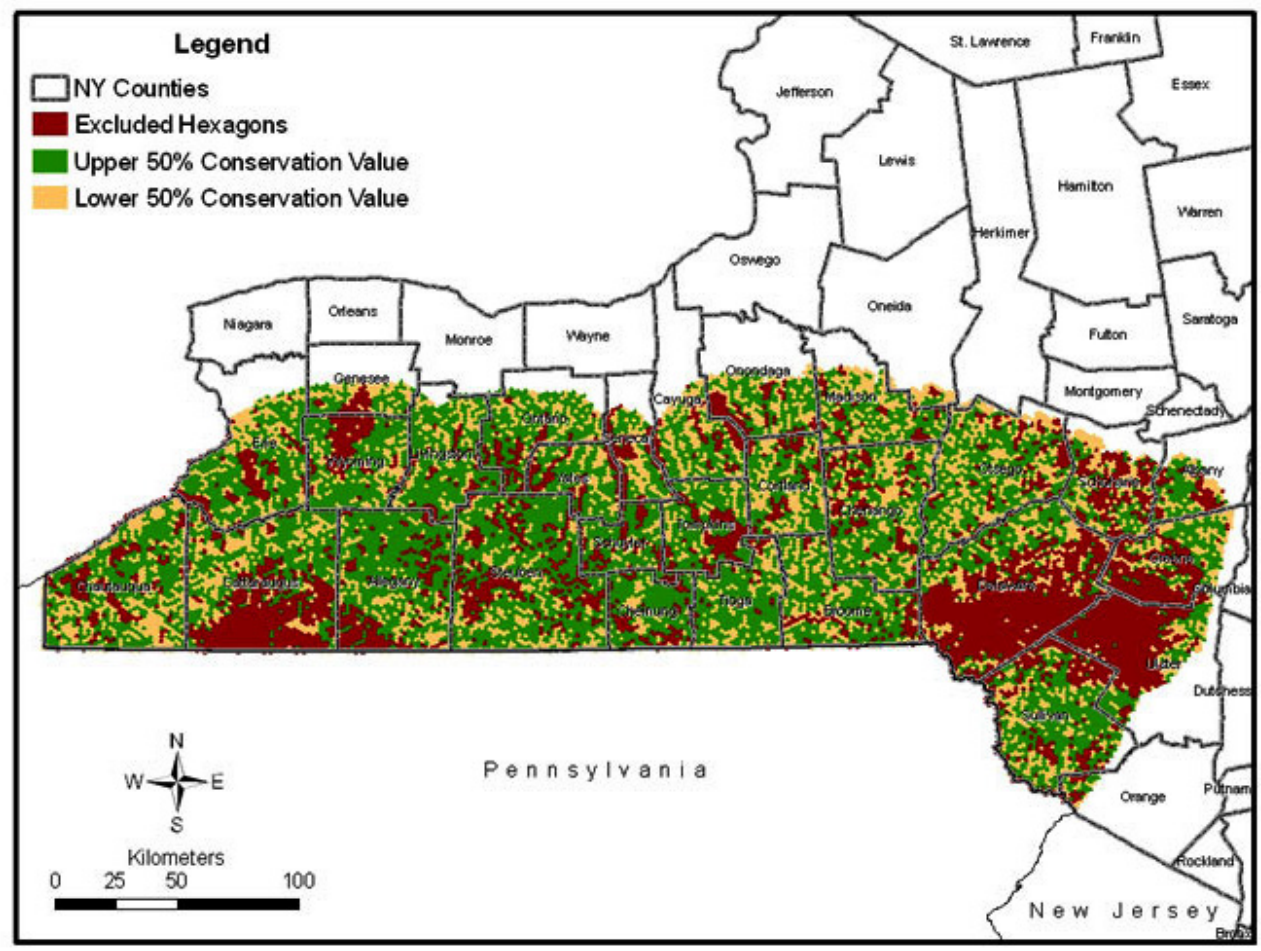

interesting that ordered selection at the town level, which aims to distribute resource access in a fair and balanced process, closely tracks the statewide ordered selection result for core forest and streams (Fig. 4a,b). In the case of grassland birds, however, results at the town level were similar, regardless of whether site selection was random or ordered by vulnerability (Fig. 4c).

\section{DISCUSSION}

With its moratorium on Marcellus Shale exploitation due to conclude, the New York State government is faced with several levels of policy decisions on how to address competing demands from different constituencies. Our study addresses three of those levels: first, whether environmental costs of exploitation are adequately addressed; second, whether economic benefits are fairly shared; and third, whether those benefits can be drawn on to reduce or mitigate the costs. Our three categories of ecological cost are not intended to be fully comprehensive or best choices; they are simply based on available information that matches the geographic scale of the question.
We focused on ecological criteria, but the underlying map layers can be used with other spatially arrayed data sets such as zones of potential soil and water contamination. They can also be modified to incorporate new estimates of shale gas production potential as a means of incorporating variation in economic potential. However, specific local impacts cannot be predicted using our approach, which is not designed as a tool for individual site selection; however, it offers two advantages over haphazard modes of planning. First, we were able to demonstrate potential cumulative impacts that vary according to apportionment strategies; second, those impacts or related parameters can be monitored to support adaptive ecosystem management (Vogt et al. 1997). Another advantage is that the hexagon grid at the scale employed obscures potentially sensitive details such as ownership or jurisdictional boundaries, which might raise political concerns beyond the scope or intent of the model. 
Fig. 4. Plots of cumulative ecological impacts under three site selection methods: statewide ranking by increasing vulnerability, town-level ranking by increasing vulnerability, and random town-level ranking. (See Methods: Selection criteria for ecological vulnerability models). (A-C) Percent disturbed values correspond to data distributions in Fig. 1A-C, respectively.

a

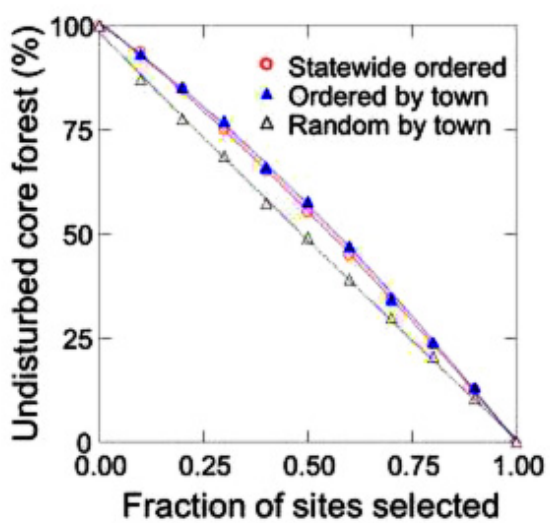

b
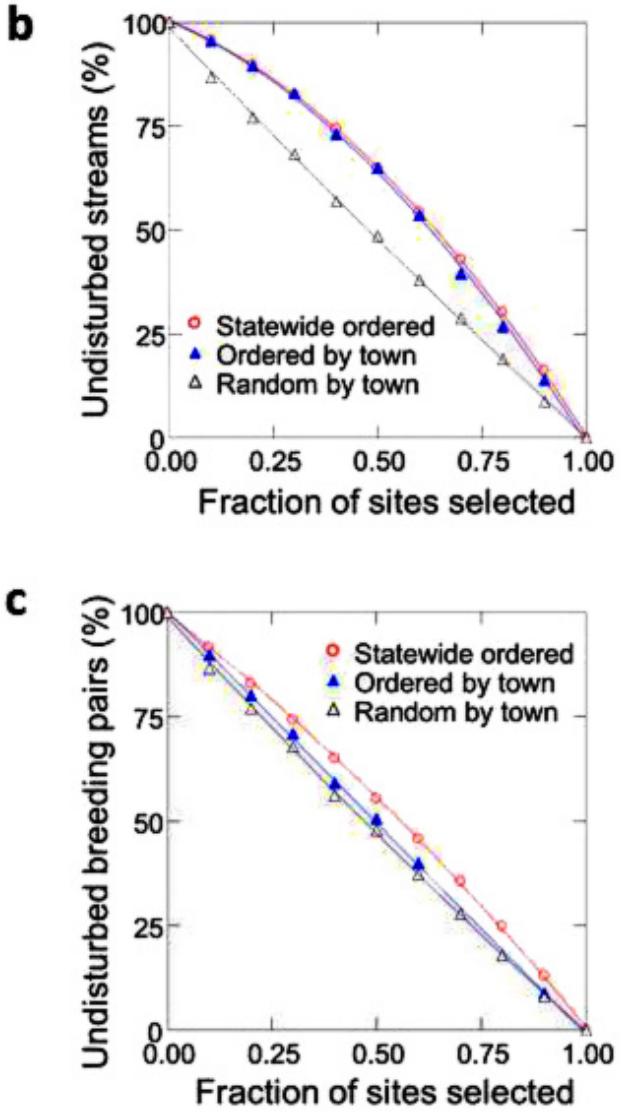

In ruling out a subset of hexagons as unsuitable, we made several assumptions that may need reconsideration. For example, our category of protected lands includes public properties and private preserves where drilling may eventually take place, either by choice or by default, such as cases where surface mineral rights are held separately. However, we did not include private lands protected by conservation easements or similar instruments, so the protected category could have applied to a larger set of hexagons. Our rule for excluding only $100 \%$ roadless hexagons could be challenged as inadequate, given that a less stringent rule would have excluded far more; for example, relaxing the threshold to $0.25 \mathrm{~km} / \mathrm{km}^{2}$ would have nearly doubled the number of excluded hexagons from 619 to 1097. In this case, however, the data set probably misses some unpaved roadways, and relaxing any of our exclusion criteria also would have led to increased redundancy (Table 2).

The criteria used to determine vulnerability rankings were limited to three independent parameters available in relatively current and comprehensive formats. Core forest is a welldeveloped concept based on decades of research into effects of habitat fragmentation (reviewed in Harrison and Bruna 1999, Fischer and Lindenmayer 2007, Collinge 2009), and retaining forest continuity is at the heart of many ecological assessments of land-use change (e.g., Heilman et al. 2002, Hawbaker et al. 2006, Jantz and Goetz 2008, Robles et al. 2008). One of the more striking results from a similar study in Pennsylvania is the extensive loss of core forest projected for the near future because of unregulated Marcellus Shale exploitation (Johnson 2010). We did not differentiate among forest cover types, but, as with exclusion criteria, our goal was to depict broad landscape patterns rather than detailed, ecosystem-specific consequences.

The second parameter, stream density, reflects natural landscape patterns and, in some cases, artificial processes. Of the three parameters, it may be the least amenable to direct ecological interpretation, but we think it is a useful metric. In the simplest sense, more mapped streams represent greater landscape complexity, which is a proxy for habitat diversity. Thus, more streams mean more aquatic and terrestrial species that are likely to need protection. It is also the variable that most closely ties natural systems to human systems. Although rural inhabitants are more likely to draw water supplies from belowground sources, small fluvial systems make important contributions to agriculture and support wildlife that are exploited for food and recreation. Higher stream densities also afford greater opportunities for industrial contamination to be transported within and among watersheds.

Grassland birds, the third parameter, are a major focus for biological conservation in much of rural New York State (Norment 2002, Morgan and Burger 2008), although they are more often associated with central prairie states (Herkert 1994, Veech 2006). Most of their remaining New York habitats are 
Table 2. Number of hexagons distributed among the six exclusion categories. Values are counts of map hexagons per category (diagonal) and counts of hexagons with overlap between category pairs (off-diagonal). Of the 5268 excluded hexagons, 952 are identified by two overlapping categories, 352 by three overlapping categories, and 18 by four overlapping categories. Categories: water $=\geq 50 \%$ surface water cover (lake or large river); slope $=50 \%$ of topography with slope $\geq 15 \%$; protected $=$ contains $\geq$ $50 \%$ cover by areas (private or public) managed for conservation or public use; wetland $=$ contains $\geq 50 \%$ cover by mapped wetland ( $\geq 5 \mathrm{ha}$ ); roadless $=0 \mathrm{~km}$ of mapped roads; streams $=$ contains $\geq 1 \mathrm{~km}$ of streams designated high quality (New York Class AA or A, Pennsylvania Class EV or HQ-CWF). (For sources, see Methods: Selection criteria for conservation vulnerability models).

\begin{tabular}{|c|c|c|c|c|c|c|}
\hline & Wetland & Water & Protected & Slope & Streams & Roadless \\
\hline Wetland & 46 & & & & & \\
\hline Water & 7 & 411 & & & & \\
\hline Protected & 6 & 31 & 1457 & & & \\
\hline Slope & 0 & 18 & 591 & 2882 & & \\
\hline Streams & 2 & 278 & 85 & 255 & 1563 & \\
\hline Roadless & 7 & 69 & 308 & 361 & 98 & 619 \\
\hline
\end{tabular}

tied to private agricultural lands (Morgan and Burger 2008), which are also among the more likely candidates for new shale gas operations (NYSDEC 2011). In this case, applying a statewide inventory of species of concern offers new information that can be applied on behalf of resource stewardship, albeit for a small subset of wild species. Comparable data are available for interior forest birds of conservation concern, but their inclusion is not likely to add substantial improvements to the model. First, much of the information would have been redundant, given their strong ties to core forest habitats; second, most of the more sensitive forest interior species are found at latitudes beyond the study area (Schlesinger et al. 2011) or at elevations well above the shale formation.

Many potentially relevant measures of ecological impacts were not included, primarily because they are not consistently mapped as statewide data sets. However, additional parameters can be introduced at local levels of the decision process. For example, records of rare and endangered species occurrences are maintained with geospatial coordinates (New York Natural Heritage Program, http://www.dec.ny.gov/anim als/65148.html), for use during individual environmental permitting and zoning reviews. Also, although we chose to forgo habitat models in favor of ground-level records, statewide habitat models are available for grassland birds or other sensitive species of concern.

\section{General properties of our approach}

Marcellus Shale exploitation is one example of the rapid spread of new forms of resource extraction in advance of close scientific scrutiny (see Schindler 2010). Our applied focus was at the level of state government for two reasons. First, in the context of shared resources, local governance has a mixed record in supporting sustainable use, particularly when it comes to addressing ecological degradation that accompanies resource exploitation (Olson 1996, Leach et al. 1999, Brown and Purcell 2005, Miller et al. 2009, Ostrom 2009). Second, in the case of Marcellus Shale resources, lessons from Pennsylvania indicate that town governments may have limited regulatory authority. In addition, state government has the better-established legal responsibility to protect publicly shared resources under the Public Trust Doctrine (Johnson and Galloway 1996, Bruskotter et al. 2011). However, there seems to be no inherent reason why our approach cannot be used outside of state-level governance.

Several general properties of our model may make it suitable for evaluating other natural resource policies with asymmetric costs and benefits. First, all data used are publicly available without costs or restrictions. Second, the underlying hexagonal grid can be modified to operate at virtually any spatial scale. Third, the vulnerability rankings and selection processes are transparent and can be reconfigured to meet the needs of other environmental impact assessments. In addition, cumulative results are summarized in a relatively simple, straightforward graphical format that allows marginal costs to be examined.

\section{CONCLUSIONS AND POTENTIAL APPLICATIONS}

Marcellus Shale gas extraction is a form of resource exploitation in which economic benefits are narrowly shared and cumulative ecological costs are broadly distributed; thus far, those costs have not been fully addressed in planning or policy. We have proposed a system for estimating some of the more obvious ecological costs that will accumulate in New York State, if and when exploitation proceeds, including a framework for redistributing cost assessments in a politically fair and transparent manner. How and when costs should be apportioned is political decision, but our results open up a new path to a reasonable decision-making process. 
Permit systems that currently apply to Marcellus Shale exploitation in New York State are designed to address local impacts and rely on land-use zoning and environmental impact assessment (NYSDEC 2011). They are not designed to assess and capture many of the broader ecological costs borne by the general public, which currently has no claim to the economic benefits from the targeted gas reserves. However, by applying an approach like ours, each potential drilling site can be assessed according to its estimated contribution to cumulative ecological costs. With respect to the loss of ecological values (estimated for core forests, natural streams, grassland birds, or any other measurable parameter), dollar amounts could be calculated on the basis of replacement values, ecosystem service values (Farber et al. 2002), or some other means, and assessed on a sliding fee scale for permits according to estimated ecological impacts. Using our selection methods would ensure two levels of fair apportionment. First, site permits would be assessed on the basis of unbiased estimates of their relative contributions to statewide ecological degradation. Second, economic benefits at the town level could be shared proportionately across the state, in an open manner supported by scientific evidence. Once assessed on this basis, permits (or similar instruments) could be bought and sold, with their values reflecting at least some of the larger ecological costs that would otherwise be distributed less fairly.

Responses to this article can be read online at: http://www.ecologyandsociety.org/voll7/iss2/art25/ responses/

\section{Acknowledgments:}

We are very grateful for critique and advice from two anonymous reviewers. Portions of this study were supported by the U.S. Fish and Wildlife Service through the New York State Wildlife Grant program and by the UAlbany Program in Biodiversity, Conservation, and Policy.

\section{LITERATURE CITED}

Briffault, R. 1990. Our localism: part I — the structure of local government law. Columbia Law Review 90(1):1-115.

Brown, J. C., and M. Purcell. 2005. There's nothing inherent about scale: political ecology, the local trap, and the politics of development in the Brazilian Amazon. Geoforum 36:607-624. http://dx.doi.org/10.1016/j.geoforum.2004.09.001

Bruskotter, J. T., S. A. Enzler, and A. Treves. 2011. Rescuing wolves from politics: wildlife as a public trust resource. Science 333:1828-1829. http://dx.doi.org/10.1126/science.12 $\underline{07803}$

Cole, N. 2010. The effect of increased salinity on diversity and abundance of diatoms. Unpublished report. Pennsylvania
State University, University Park, Pennsylvania, USA. [online] URL: http://www.marcellus.psu.edu/resources/PDFs/ salinity.pdf.

Coleman, J. L., R. C. Milici, T. A. Cook, R. R. Charpentier, M. Kirschbaum, T. R. Klett, R. M. Pollastro, and C. J. Schenk. 2011. Assessment of undiscovered oil and gas resources of the Devonian Marcellus Shale of the Appalachian Basin Province, 2011. Fact Sheet 2011-3092. U.S. Geological Survey, Reston, Virginia, USA. [online] URL: http://pubs.usgs.gov/fs/2011/3092/

Collinge, S. K. 2009. Ecology of fragmented landscapes. Johns Hopkins University Press, Baltimore, Maryland, USA.

Considine, T., R. Watson, R. Entler, and J. Sparks. 2009. An emerging giant: prospects and economic impacts of developing the Marcellus Shale natural gas play. Unpublished report. Pennsylvania State University, University Park, Pennsylvania, USA. [online] URL: http://marcelluscoalition. org/wp-content/uploads/2010/05/EconomicImpactsofDevelop ingMarcellus.pdf.

Entrekin, S., M. Evans-White, B. Johnson, and E. Hagenbuch. 2011. Rapid expansion of natural gas development poses a threat to surface waters. Frontiers in Ecology and the Environment 9(9):503-511. http://dx.doi.org/10.1890/110053

Farber, S. C., R. Costanza, and M. A. Wilson. 2002. Economic and ecological concepts for valuing ecosystem services. Ecological Economics 41(3):375-392. http://dx.doi.org/10.1016/ $\underline{\text { S0921-8009(02)00088-5 }}$

Fischer, J., and D. B. Lindenmayer. 2007. Landscape modification and habitat fragmentation: a synthesis. Global Ecology and Biogeography 16(3):265-280. http://dx.doi.org/1 0.1111/j.1466-8238.2007.00287.x

Fountain, H. 2012. Disposal halted at well after new quake in Ohio. New York Times 1 January 2012, A11. [online] URL: http://www.nytimes.com/2012/01/02/science/earth/youngstowninjection-well-stays-shut-after-earthquake.html? $\mathrm{r}=1$.

Gibbs, J. P. 2000. Wetland loss and biodiversity conservation. Conservation Biology 14(1):314-317. http://dx.doi.org/10.1046/ j.1523-1739.2000.98608.x

Gould, W. A., and M. Solórzano. 2009. Multiple scale integrated range maps for modeling predicted distributions of vertebrate species in the U.S. Virgin Islands. Gap Analysis Bulletin 16:9-20.

Harrison, S., and E. Bruna. 1999. Habitat fragmentation and large-scale conservation: What do we know for sure? Ecography 22(3):225-232. http://dx.doi.org/10.1111/j.1600-0 587.1999.tb00496.x

Hawbaker, T. J., V.C. Radeloff, M. K. Clayton, R. B. Hammer, and C. E. Gonzalez-Abraham. 2006. Road development, housing growth, and landscape fragmentation in northern 
Wisconsin: 1937-1999. Ecological Applications 16 (3):1222-1237. http://dx.doi.org/10.1890/1051-0761(2006)016 [1222:RDHGAL]2.0.CO;2

Heilman, G. E., J. R. Strittholt, N. C. Slosser, and D. A. Dellasala. 2002. Forest fragmentation of the conterminous United States: assessing forest intactness through road density and spatial characteristics. BioScience 52(5):411-422. http://d x.doi.org/10.1641/0006-3568(2002)052[0411:FFOTCU]2.0.CO;2

Herkert, J. R. 1994. The effects of habitat fragmentation on Midwestern grassland bird communities. Ecological Applications 4(3):461-471. http://dx.doi.org/10.2307/1941950

Jacquet, J., and R. Stedman. 2009. Emerging trends in the Marcellus Shale. Research and Policy Brief Series 30. Cornell University, Ithaca, New York, USA. [online] URL: http://dev soc.cals.cornell.edu/cals/devsoc/outreach/cardi/publications/ upload/07-2009-RPB.pdf.

Jantz, P., and S. Goetz. 2008. Using widely available geospatial data sets to assess the influence of roads and buffers on habitat core areas and connectivity. Natural Areas Journal 28(3):261-274. http://dx.doi.org/10.3375/0885-8608(2008)28 [261:UWAGDS]2.0.CO;2

Johnson, N. 2010. Pennsylvania energy impacts assessment. Report 1: Marcellus Shale natural gas and wind. Unpublished report. Nature Conservancy Pennsylvania Chapter, Harrisburg, Pennsylvania, USA. [online] URL: http://www.n ature.org/media/pa/pa_energy assessment report.pdf.

Johnson, R. W., and W. C. Galloway. 1996. Can the public trust doctrine prevent extinctions? Pages 157-164 in W. J. Snape III, editor. Biodiversity and the law. Island Press, Washington, D.C., USA.

Kraft, M. E. 2004. Environmental policy and politics. Third edition. Pearson Longman, New York, New York, USA.

Leach, M., R. Mearns, and I. Scoones. 1999. Environmental entitlements: dynamics and institutions in community-based natural resource management. World Development 27 (2):225-247. http://dx.doi.org/10.1016/S0305-750X(98)00141-7

Ludwig, D., R. Hilborn, and C. Walters. 1993. Uncertainty, resource exploitation, and conservation: lessons from history. Science 260:17,36. http://dx.doi.org/10.1126/science.260.5104.17

Miller, J. R., M. Groom, G. R. Hess, T. Steelman, D. L. Stokes, J. Thompson, T. Bowman, L. Fricke, B. King, and R. Marquardt. 2009. Biodiversity conservation in local planning. Conservation Biology 23(1):53-63. http://dx.doi.org/10.1111/ j.1523-1739.2008.01110.x
Morgan, M., and M. Burger. 2008. A plan for conserving grassland birds in New York. Final report to the New York State Department of Environmental Conservation under contract C005137. Audubon New York, Ithaca, New York, USA. [online] URL: http://www.docstoc.com/docs/41837645/ A-Plan-for-Conserving-Grassland-Birds-in-New-York.

Nelson, E., G. Mendoza, J. Regetz, S. Polasky, H. Tallis, D. R. Cameron, K. M. A. Chan, G. C. Daily, J. Goldstein, P. M. Kareiva, E. Lonsdorf, R. Naidoo, T. H. Ricketts, and M. R. Shaw. 2009. Modeling multiple ecosystem services, biodiversity conservation, commodity production, and tradeoffs at landscape scales. Frontiers in Ecology and the Environment 7(1):4-11. http://dx.doi.org/10.1890/080023

New York State Department of Environmental Conservation (NYSDEC). 2011. Supplemental generic environmental impact statement on the oil, gas and solution mining regulatory program: well permit issuance for horizontal drilling and high-volume hydraulic fracturing to develop the Marcellus Shale and other low-permeability gas reservoirs. Revised draft. New York State Department of Environmental Conservation, Albany, New York, USA. [online] URL: http:/ /www.dec.ny.gov/data/dmn/rdsgeisfull0911.pdf.

Norment, C. 2002. On grassland bird conservation in the Northeast. Auk 119(1):271-279. http://dx.doi.org/10.1642/000 4-8038(2002)119[0271:OGBCIT]2.0.CO;2

Olson, T. G. 1996. Biodiversity and private property: conflict or opportunity? Pages 67-79 in W. J. Snape III, editor. Biodiversity and the law. Island Press, Washington, D.C., USA.

Osborn, S. G., A. Vengosh, N. R. Warner, and R. B. Jackson. 2011. Methane contamination of drinking water accompanying gas-well drilling and hydraulic fracturing. Proceedings of the National Academy of Sciences 108(20):8172-8176. http://dx.d oi.org/10.1073/pnas.1100682108

Ostrom, E. 2009. A general framework for analyzing sustainability of social-ecological systems. Science 325:419-422. http://dx.doi.org/10.1126/science.1172133

Patuxent Wildlife Research Center. 2004. Geographic information products from the North American breeding bird survey version 2004.1: route-level and polygon coverages. $\mathrm{U}$. S. Geological Survey, Laurel, Maryland, USA. [online] URL: http://137.227.242.23/bbs/geographic information/ geographic_information_products_htm.

Penn State Institutes of the Environment (PSIE). 2008. Streams Chapter 93 designated use. Pennsylvania Spatial Data Access (PASDA), Pennsylvania State University, College Park, Pennsylvania, USA. Pennsylvania Spatial Data Access [online] URL: http://www.pasda.psu.edu/uci/MetadataDisplay. aspx?entry=PASDA\&file=StreamsCH93DesignatedUse2010 12. $\underline{\mathrm{xml} \& \text { dataset }=1098}$. 
Pennsylvania Department of Transportation (PADOT). 2011a. Local roads. Pennsylvania Department of Transportation, Harrisburg, Pennsylvania, USA. Pennsylvania Spatial Data Access [online] URL: http://www.pasda.psu.edu/ uci/MetadataDisplay.aspx?entry=PASDA\&file $=$ PaLocalRoads2011_01.xml\&dataset $=1038$.

Pennsylvania Department of Transportation (PADOT). 2011b. State roads. Pennsylvania Department of Transportation, Harrisburg, Pennsylvania, USA. Pennsylvania Spatial Data Access [online] URL: http://www.pasda.psu.edu/ uci/MetadataDisplay.aspx?entry=PASDA\&file $=$ PaStateRoads2011_01.xml\&dataset=54.

Robles, M. D., C. H. Flather, S. M. Stein, M. D. Nelson, and A. Cutko. 2008. The geography of private forests that support at-risk species in the conterminous United States. Frontiers in Ecology and the Environment 6(6):301-307. http://dx.doi.org $\underline{110.1890 / 070106}$

Schindler, D. 2010. Tar sands need solid science. Nature 468:499-501. http://dx.doi.org/10.1038/468499a

Schindler, S., K. Poirazidis, and T. Wrbka. 2008. Towards a core set of landscape metrics for biodiversity assessments: a case study from Dadia National Park, Greece. Ecological Indicators 8(5):502-514. http://dx.doi.org/10.1016/j.ecolind.2 $\underline{007.06 .001}$

Schlesinger, M. D., J. D. Corser, K. A. Perkins, and E. L. White. 2011. Vulnerability of at-risk species to climate change in New York. New York Natural Heritage Program, Albany, New York, USA. [online] URL: http://www.natureserve.org/ prodServices/climatechange/pdfs/ccvi report ny.pdf.

Soeder, D. J., and W. M. Kappel. 2009. Water resources and natural gas production from the Marcellus Shale. U.S. Geological Survey Fact Sheet 2009-3032. U.S. Geological Survey, Baltimore, Maryland, USA. [online] URL: http://ww w.svnva.org/ass/library/42/marcellus_usgsreport.pdf.

Spence, M. H., and D. White. 1992. EMAP sampling grid technical report. ManTech Environmental Technology, U.S. EPA Environmental Research Laboratory, Corvallis, Oregon, USA.

Tavernise, S. 2011. As gas drilling spreads, towns stand ground over control. New York Times 15 December 2011, A20. [online] URL: http://www.nytimes.com/2011/12/15/us/townsfighting-to-stand-ground-against-gas-drillers.html?pagewanted= all.

Urbina, I. 2011a. Regulation lax as gas wells' tainted water hits rivers. New York Times 27 February 2011, A1. [online] URL: http://www.nytimes.com/2011/02/27/us/27gas.html? r $=1$ \&pagewanted=all
Urbina, I. 2011b. Pressure limits efforts to police drilling for gas. New York Times 04 March 2011, A1. [online] URL: http ://www.nytimes.com/2011/03/04/us/04gas.html?pagewanted= all.

Urbina, I. 2011c. E.P.A. steps up scrutiny of pollution in Pennsylvania rivers. New York Times 08 March 2011, A12. [online] URL: http://www.nytimes.com/2011/03/08/science/ earth/08water.html

U.S. Environmental Protection Agency (USEPA). 2011. Draft plan to study the potential impacts of hydraulic fracturing on drinking water resources. EPA/600/D-11/001. U.S. Environmental Protection Agency, Washington, D.C., USA. [online] URL: http://www.epa.gov/hfstudy/HFStudyPlanDra ft SAB 020711.pdf.

U.S. Fish and Wildlife Service (USFWS). 2009. National wetlands inventory - Pennsylvania. U.S. Fish and Wildlife Service, Washington, D.C., USA. Pennsylvania Spatial Data Access [online] URL: http://www.pasda.psu.edu/uci/Metadat aDisplay.aspx?entry=PASDA\&file=NWI PA.xml \&dataset $=1457$

U.S. Geological Survey (USGS). 2000. 7.5 minute digital elevation models (DEM) for Pennsylvania 10 meter. U.S. Geological Survey, Reston, Virginia, USA. Pennsylvania Spatial Data Access [online] URL: http://www.pasda.psu.edu/ uci/MetadataDisplay.aspx?entry=PASDA\&file=dem 10 meter. xml\&dataset $=99$.

U.S. Geological Survey (USGS). 2009. Protected area database of the United States (PAD-US v1). USGS National Gap Analysis Program. U.S. Geological Survey, Reston, Virginia, USA. [online] URL: ftp://ftp.gap.uidaho.edu/outgoing/ PADUS_v1.

Veech, J. A. 2006. A comparison of landscapes occupied by increasing and decreasing populations of grassland birds. Conservation Biology 20(5):1422-1432. http://dx.doi.org/10. 1111/j.1523-1739.2006.00487.x

Vogt, K., J. C. Gordon, J. P. Wargo, D. J. Vogt, H. Asbjornse, P. A. Palmiotto, H. J. Clark, J. L. O'Hara, W. S. Keaton, T. Patel-Weyn, and E. Witten. 1997. Ecosystems: balancing science with management. Springer-Verlag, New York, New York, USA. 